\title{
Encounters with strangeness: Intercultural learning in an engineering course
}

\author{
Jan Van Maele, Steven Schelkens, and Katrien Mertens
}

\begin{abstract}
This paper reports on an intervention whereby a critical approach to intercultural communication is implemented in a module for undergraduate students of engineering technology. The module centers on an encounter in which small teams engage with people and practices that represent cultural strangeness to them. A qualitative, exploratory study was carried out on how participating students perceive strangeness, on their motives for selecting their encounter, and on the insights as they reported and demonstrated them in their project reports. Students confirmed the primacy of first-hand experience in intercultural learning, and pointed at an open mind, a nonessentialist view of culture, and an awareness of stereotyping as key takeaways from the project. Providing additional teacher guidance could further support students in their acquisition of critical understanding, for instance through the development of validated (self-)assessment tools. The authors conclude that the described project can help to fill the observed lack of intercultural communication practices from a critical, non-essentialist perspective in engineering education. More generally, this study contributes to a wider pedagogy of encounter by elucidating the concept of strangeness as a linking concept for examining underlying dynamics in intercultural interaction.
\end{abstract}

Keywords: critical interculturality; engineering education; intercultural encounters; strangeness; student perspectives

Received 14 December 2020; revised version received 31 May 2021; accepted 17 October 2021. Corresponding author: Jan Van Maele, KU Leuven, Belgium (jan.vanmaele@kuleuven.be).

\section{Introduction}

Accreditation bodies and professional organizations across different continents have repeatedly stipulated that engineering graduates should be able to collaborate within diverse teams in international contexts, communicate with engineers and non-engineers alike, and make informed judgments that take in the impact of engineering solutions in global, ethical, societal contexts (ABET, 2019; EURANEE, 2015; FEIAP, 2010/2018). The path to implement these desirable 
learning outcomes in the engineering curriculum, however, has not been smooth (Kjellgren, 2020; Van Maele \& Vassilicos, 2015). Even in places where educational interventions have been implemented to promote such outcomes, they have largely been informed by an essentialist approach rather than by a culture-as-construct perspective that prioritizes small cultures and interpretivist understanding (Handford et al, 2019). In cases where intercultural communication has been taught through experiential methods, engineering educators have called for studies on how to make training more active by providing students opportunities to have authentic intercultural encounters (Rio-García \& Fielden, 2020).

This paper takes up these calls from engineering educators and professional organizations by discussing one educational intervention for undergraduate engineering students, namely a team project that revolves around an encounter with strangeness. The project thereby helps to fill the detected dearth of intercultural communication practices from a culture-as-construct perspective in the engineering education field. At a more general level, the study contributes to a 'pedagogy of encounter' (Hanchin, 2019) in intercultural education by elucidating the concept of strangeness as a 'linking concept' (Gudykunst \& Kim, 1997) for examining underlying dynamics in intercultural interaction, and by identifying theoretical and practical challenges of implementing strangeness in concrete educational interventions.

As practitioners, we set up this study to reflect on our praxis and better understand how our students engage with the project. Two research questions have guided us in our exploration: (1) How do students perceive strangeness? and (2) What have they learned from their encounter with strangeness? The first question relates to the initial stage of the team project and the answers can help us to better support students in defining projects with high potential for intercultural learning. The second question refers to reported and demonstrated learning outcomes, and findings can shed some light on the effectiveness of the project. After a review of the literature on intercultural encounters as encounters with strangeness, we shall describe the educational setting of the project. Then we turn to an analysis of the research questions, after which the concept of strangeness is revisited and conclusions are drawn for a praxis of fostering critical interculturality in higher education. 


\section{Intercultural learning through encounters with strangeness}

\section{Intercultural encounters}

What qualifies as an intercultural encounter? Van Maele and Mertens (2014) point out that encounters cannot a priori qualify as intercultural on the basis of the presence or absence of differences in group memberships. Instead, an encounter is intercultural when cultural dimensions are made topical or are experienced as significant by one or more participants in the encounter. Likewise, for Borghetti (2017), the intercultural resides in 'how individuals socially position themselves in interactions ... to their awareness of such positioning, and to their willingness and ability to recognize and negotiate the others' multiple identities as much as their own' (p. 2). This focus on 'the now and then of interaction, beyond generalizations of contexts and interlocutors' is necessary to speak of 'critical interculturality', Dervin $(2017$, p. 1) argues. The noun 'interculturality' is chosen to highlight that culture is regarded as a fluid and continuous process rather than a fixed state (Dervin, 2016). As such, it corresponds with a non-essentialist view (Holliday, 1999) according to which culture is approached as a construct rather than a given (Handford et al, 2019). The perspective is called 'critical' because it struggles against solid identities and requires 'questioning the terms, concepts and notions that we use to discuss these topics' (Simpson \& Dervin, 2019, p. 115). The present study aligns with critical interculturality as a theoretical perspective for intercultural encounters, and turns to Holliday, Kullman and Hyde's (2017) non-essentialist framework of disciplines for intercultural communication for a practical translation of this perspective into an instructional tool for the team project on encounters with strangeness.

Holmes and O'Neill (2012) highlight 'the importance of the intercultural encounter as the place where individuals can shift their focus away from an external evaluation of the Other to an inward contemplation of their own intercultural competence' (p. 707). But who are these others we encounter, and how can these encounters be capitalized upon as a strategy for intercultural learning? In order to address these questions, we now turn to voices in the literature from a wide range of disciplines, including philosophy, sociology, anthropology, critical pedagogy, language education, and intercultural studies. In this overview the term 'strangeness' will be used as a 'linking concept' (Gudykunst \& Kim, 1997, p. 27) to examine the underlying dynamics in all interactions with the unfamiliar other, regardless of whether the strangeness is situated in oneself, other persons, in the relationship, the subject, or the environment. 


\section{Intercultural encounters as encounters with strangeness}

The notion of strangeness has been intricately connected to that of intercultural encounters. Hoffman and Verdooren (2018) go as far as equating them when they define an intercultural situation as 'an experience of strangeness due to unfamiliarity with a difference of any kind' (p. 54). Earlier, Hall (1976) already conjured up the metaphor of the sailor who finds themselves in unknown waters:

Most cultural exploration begins with the annoyance of being lost. The control systems of the mind signal that something unexpected has arisen, that we are in uncharted waters and are going to have to switch off the automatic pilot and man the helm ourselves. (p. 46)

The willingness to venture into uncharted waters and the adeptness at navigating them have widely been seen as essential components of what it means to be interculturally competent. Ting-Toomey (1999) notes that it is through 'encountering a dissimilar other' and 'facing our own discomfort' that we question our routine ways and learn to stretch and grow (p. 8). Similarly, the intercultural scholars in Deardorff's (2006) Delphi study identify 'curiosity and discovery (tolerating ambiguity and uncertainty)' — which 'imply a willingness to risk and to move beyond one's comfort zone' (Deardorff, n.d.) - as a foundational trait for the development of intercultural competence (p. 254). Prechtl and Lund (2007) sketch an intercultural development path for this trait, going from adopting a tolerant attitude when uncertainty arises from cultural difference, over viewing the unfamiliar as an interesting challenge, to the ability to cope with ambiguous situations involving serious inner moral conflicts (p. 476).

The question of what constitutes strangeness, where to situate it, and how to respond to it indeed has a long tradition in intercultural thought and beyond. For our purposes we here make a rough but useful distinction between 'strangeness as unfamiliarity' and 'strangeness as alterity'. Srubar (2005), drawing on the work of the sociologist Schutz, in this sense speaks of 'comparative' versus 'existential' strangeness. Comparative strangeness allows for 'nuances and gradations that are dependent on the extent of the reciprocity of perspectives with which everyday actors encounter each other', underpinned by the supposition that 'you would see what I see if you were in my position' (Srubar, 2005, p. 244-245). Existential strangeness, on the other hand, cannot be deleted through familiarization. An example is Lévinas' concept of alterity (alterité). For Lévinas, 'alterity is encountered as a "stranger" and strangeness itself bearing no common or comparable category' notwithstanding our intentions to circumscribe the stranger's identity (Huett \& Goodman, 2014, p. 82). Yet, the very fact that there is a part of strangeness that we cannot reduce to our pre-conceived terms in the process of 
interpretation also harbors an opportunity for opening up and discovery. Jullien (2009/2011) offers the here useful notion of 'divergence' between cultures as a tool for exploration: 'divergence (écart) sets what it has separated in tension and discovers one through the other, reflects one in the other'; divergence 'allows another perspective to emerge, it loosens, or exposes, a fresh enticing possibility (and adventure)' (p. 27). This notion of divergence is reminiscent of the concepts 'third space' in postcolonial critical theory (Bhabha, 1994) and 'third culture' in language education (Kramsch, 2011) as processes of meaning making at the boundaries of and beyond the dualities of cultures (MacDonald, 2019).

From the discussion so far, it might seem as if strangeness is only to be found outside our familiar surroundings. In fact, the opposite has been argued: strangeness can be found amidst us as well as within us. Simmel's (1908/1999) seminal essay depicts strangeness as a newcomer living in our midst yet distant from us. It has been argued that Simmel's stranger can no longer reflect contemporary urban life, though, and that strangeness has become universalized; that we are now all strangers in a world that is increasingly characterized by superdiversity (Marotta, 2012). What is more, we are strangers not just to the others around us, but also to ourselves: 'Strangely, the stranger lives within us: he is the hidden face of our identity’ (Kristeva, 1988, p. 9; our translation).

Irrespective of whether it is situated outside our circles, in our midst, or inside our selves, strangeness can be appreciated as a productive process that is in constant flux. This is not surprising since 'strangeness is a gradual concept and in the end a subjective one' (Verdooren, 2014, p. 17). Building on the philosopher Nauta, Harbers (2010) discusses the ambivalence of the confrontation with the strangeness of the stranger: 'it makes us question familiar frameworks that we use in a cognitive and normative sense to acquaint ourselves with the world around us', thereby widening our horizon. At the same time, strangeness alienates us from ourselves. As a result, a productive dialectic arises: 'familiarity becomes strange to us, while strangeness becomes slightly more familiar' (p. 11).

\section{Towards encounters with strangeness as a pedagogic strategy}

The dialectics between strangeness and familiarity also have a practical relevance for engaging with strangeness. Ethnographic fieldworkers need 'familiarization strategies' to develop an understanding from within (e.g., through immersion) as well as 'estrangement strategies' for making the familiar strange. The latter can be done by looking for the unexpected or the 'irrational' in the data, or by adopting an unusual theoretical perspective to make overly familiar data look strange again (de Jong, Kamsteeg, \& Ybema, 2013). In religious education, Hanchin (2019) explains how Pope Francis' praxis of encounter can be applied in a pedagogy that is particularly relevant in these polarizing times. This pedagogy of encounter is 
realized along the steps of displacement, dialogue, and discernment (of truth and value). In teacher education, Polymenakou (2019) demonstrates the impact on student teachers' intercultural learning of 'pedagogical intercultural community encounters', which 'involve first-hand, in person interactions off campus, but locally, with individuals that participants would perceive as "others"' (p. 205). As a final example, in intercultural language pedagogy, Dasli (2011) applies Harbermas' theory of communicative action to real-life encounters between the Self and the Other to help students control their fear of the unknown.

Building on a well-established tradition that emphasizes experiential and experimental learning (e.g., Dewey 1938/2015; Seaman, Brown, \& Quay, 2017), intercultural educators and researchers have also addressed practical issues of a pedagogy of encounters. The question of how to engage with strangeness is one for which educators have found inspiration in ethnographic research. Holmes and O'Neill $(2010 ; 2012)$ highlight the effectiveness of combining interpersonal intercultural interactions with autoethnographic self-reflections. Building on Geertz' (1973) notion of 'thick description', Samudra (2008) explains how 'thick participation' can serve as a way of learning embodied cultural practices such as martial arts to access 'cultural knowledge recorded first in the anthropologist's body and only later externalized as visual or textual data for purposes of analysis' (p. 667). The question of how much strangeness is conducive to learning has regularly been framed as the search for an optimum level of arousal for achieving peak performance, known as the Yerkes-Dodson law, which has been popularized in experiential training as Rohnke's Comfort-Stretch-Panic model (Limacher, n.d.). It is in this wider pedagogic tradition of encounters that the project to which we will now turn is to be situated.

\section{The Encounters with Strangeness Project}

Encounters with Strangeness (EWS) is a team project that invites students to step out of their comfort zone and personally engage with people and practices that represent cultural strangeness to them. The project constitutes the central component of a compulsory module on intercultural communication for bachelor students of engineering technology at a leading university in Flanders, Belgium. The module is organized so that students of both language tracks, Dutch and English, can mingle and collaborate with each other. It aligns with the policy plan that highlights the development of global skills on campus as part of a wider internationalization-at-home agenda. In recent years, the module has annually welcomed around 400 students, who form close to 100 teams coached by the first and second author of this paper. Students are told to compose teams that are 
characterized by cultural diversity in the broadest sense of the word. The module represents a student time investment of approximately 40 hours (1.5 ECTS) over the course of three months. Half the time is dedicated to the project itself; the other half to preparatory activities aimed at sensitizing students to foundations of qualitative research and fostering a critical approach to intercultural communication, as implemented in Holliday et al. (2017) and IEREST (2015). The former textbook with its two dozen disciplines for intercultural communication centering on the themes Identity, Othering, and Representation constitutes the principal knowledge base of the module. Students are expected to demonstrate that they are able to apply those disciplines in the way in which they conduct their project and report on it during two tutorials and a 2,500 words end-of-term report.

EWS induces students to welcome the unfamiliar and to learn to prepare for the unexpected in their professional and personal lives. At the outset, each team formulates a question about something or someone that represents (cultural) strangeness to them: 'What does it feel like to go zero-waste and what drives the young people who pursue this lifestyle?'; 'How do Jehovah's Witnesses view science?'; or 'How do our pre-conceived views on student-parents stand up to the experiences of the young student-mothers we will interview?' The actual encounter provides the context for collecting data in view of answering their question. In the process, students are expected to demonstrate openness, curiosity, and respect towards the 'small cultures' (Holliday, 1999) they explore. In order to create an optimal learning experience, teams are instructed to propose projects that require a fair amount of stretching beyond their comfort zones.

The instructions suggest several complementary ways of engaging with strangeness. They include observing a social setting that is strange to the students, meeting people that have been strangers, engaging with a cultural practice that is novel to them, and examining (self-)representations of a small culture with which they are not familiar. For example, a team consisting of home students who have never interacted with compatriots who identify as Muslims could visit a mosque, approach the faithful after the service, interview the imam, and keep journals in which they reflect on prevailing stereotypes around Muslims in peer group or media discourses and on their evolving worldview. Each team meets twice with their instructor during the project: a first tutorial focuses on the definition of their project; the other takes place after the data have been collected. These tutorials serve to guide students in taking a critical-appreciative stance towards their encounters and reflecting on how their relation with 'strangeness' has evolved in the course of the project.

In order to avoid imposing any interpretations of 'strangeness', which would contradict its dynamic and subjective nature, the concept remains undefined in the project instructions. As a result, students have to address within their team 
what constitutes strangeness to them and how to engage with it in their projects. The instructions for the final report stipulate that students also state their motives for choosing a particular project and articulate what insights they have gained from their explorations. The responses to these questions constitute the principal data that we analyzed for this paper in order to obtain a better understanding of how students perceive, approach, and experience strangeness in the context of their encounters.

\section{Studying the EWS project}

Based on the team reports of the previous two academic years, a qualitative, exploratory study was carried out to gain more insight into how students view and implement strangeness in the EWS project. The purpose of the study was to use the results as a basis for deeper reflection on our practice and adjustments for enhancing the students' learning experience. The fact that the study was jointly conducted by two instructors of the module and a colleague from another institution allowed us to combine inside and outside perspectives. The following research questions were formulated for the study: (1) How do students perceive strangeness in the definition of their project? To answer this question, we considered students' choices of their objects of strangeness and of the methods through which they engaged with strangeness. We also examined the motives they cited for the choices they made. (2) What have students learned from their encounter with strangeness project? To answer this second question, we considered the insights as students reported them and as they demonstrated them in the written team reports.

Between them, the first two authors of this paper were already familiar with all reports $(\mathrm{N}=190)$ as they had each coached half the student teams and marked the corresponding reports. Through purposive sampling (Devers \& Franklin, 2000) a set of 20 information-rich reports were selected for standardization practice by all three authors in which iterations of independent analysis alternated with interpretative discussions until conformity of analysis practice was reached. Driven by the research questions, a top-down process of thematic analysis (Braun \& Clarke, 2006) was then conducted for the full set of reports until the point of data saturation (Moser \& Korstjens, 2018). This proved to be a fruitful approach for teasing out the motives and insights reported by the students, resulting in the thematic maps below and the coding tables with illustrative quotes in the appendix. Concerning the objects of strangeness and engagement methods, a more straightforward categorization appeared sufficient as a method of analysis. Finally, even though a full inquiry into the demonstrated gains is beyond the scope of this study, a closer reading of one report illustrates how the earlier cited disciplines of intercultural communication (Holliday et al., 2017) could be used as a tool for analyzing the extent to which students demonstrate declarative and procedural understanding of critical interculturality. 


\section{Student engagement with the EWS project}

In this section, we present the results of the analysis of each research question. We also indicate briefly how the findings have been helpful in our educational praxis.

RQ1: How do students perceive strangeness in the definition of their project?

In order to gain some insight into what initially drew teams to the project, we first considered the motives students cited for selecting their subject. As shown in Figure 1 , student motives can be divided in two types. The first type, because-of-what motives, concerns motives based on some prior relation between the team and the subject, towards which a degree of openness is displayed. These interests can be related to different values, coded as practicality, topic, emotion, and opportunity (see the coding table and illustrative quotes from student reports in Appendix 1). For example, during a preliminary discussion, one team valued a project on refugees as both topical and emotional, considering the family history of three of its members. On top of this, one team member saw the project as an opportunity to explore this history with her parents, who 'still have difficulty with opening up about this topic ... to understand her parents better ... in the hope that one day she could have an open and honest conversation with her parents.' The second type, for-what-purpose motives, refers to the team's expectations of how their openness could lead to a greater understanding of what used to be strange, to changes in their own views or in the views of others, and to gaining some future benefit such as being 'more prepared to raise our own children in a different culture from our home cultures.' We have found this overview of motives helpful in coaching student teams to define more adequate project proposals that combine several motives and thereby capture the genuine interest of each student. 


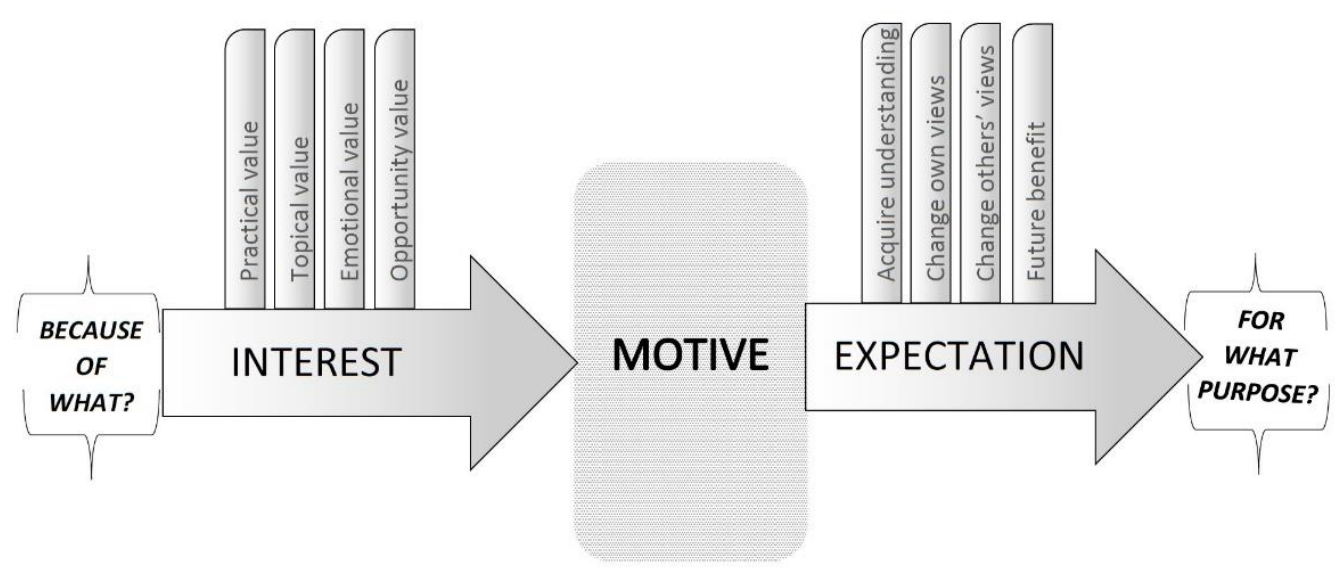

Figure 1. Thematic map of reported motives (based on the coding table in Appendix 1).

Next, we considered the nature of the relation that students held with the chosen subject for their project. The matrix in Figure 2 presents four basic categories generated by interlacing the two dimensions of (un)familiarity that students refer to in their reports, namely contact and awareness. For each dimension, a rough distinction was made between teams reporting to have no or hardly any familiarity with their subject and teams reporting more familiarity.

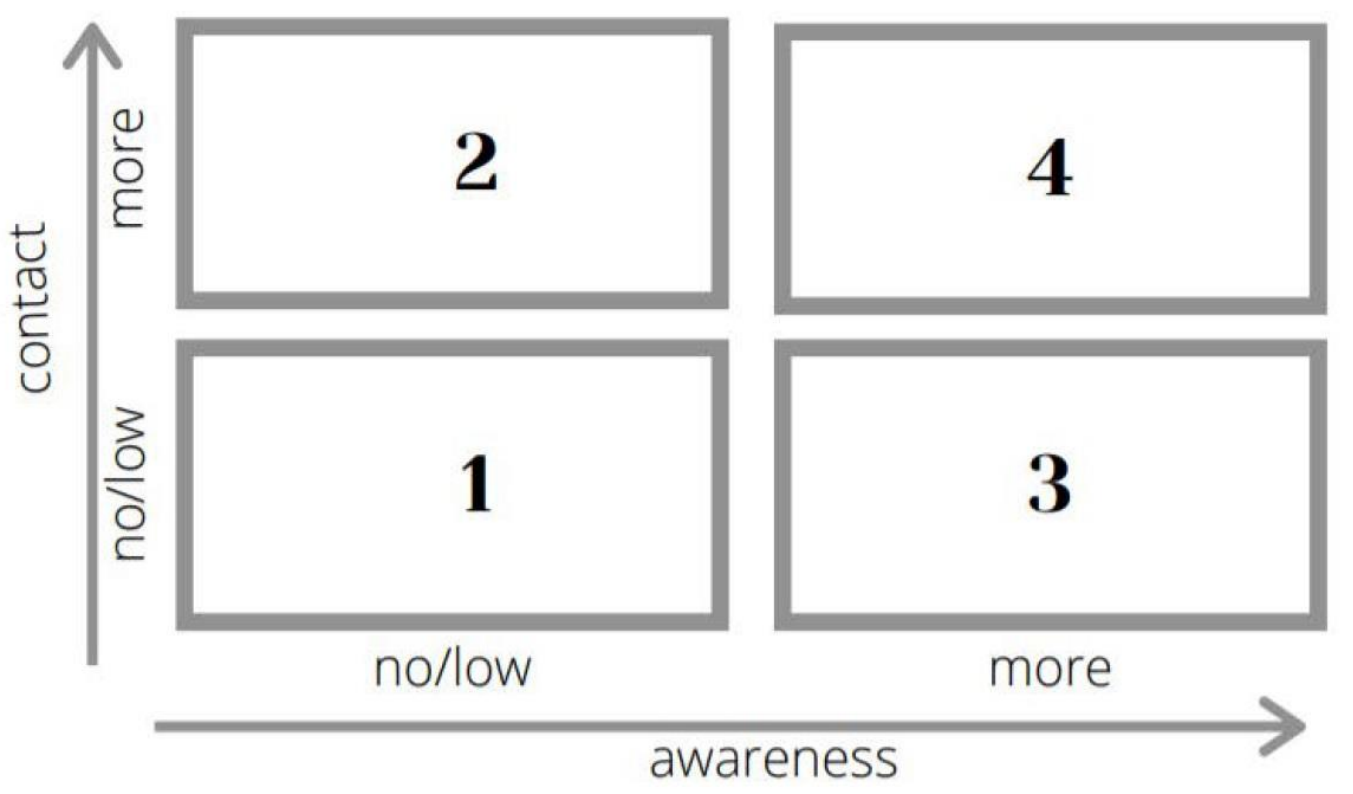

Figure 2. Strangeness in the subject of the EWS projects. 
Reported contact represents the social dimension of strangeness. It refers to the scope and intensity of contact team members report to have had prior to the project with representatives from the 'strange' culture. Reported awareness stands for the cognitive dimension of strangeness and refers to the teams' alleged awareness or knowledge about their topic. Teams were considered to have 'more awareness' if they indicated that one or more members had some knowledge or understanding, regardless of the accuracy and the source (be it through direct contact or from the media, school, hearsay ...) of that knowledge. Here is an example for each category in the figure:

- Category 1: A team that had never attended an event of a religion different from their own decides to observe three religious meetings that no one in the team was familiar with [Report 19-J-39].

- Category 2: Despite the fact that team members have lived nearby an Orthodox Jewish community and have regularly passed them in the street, they realize they have no knowledge of the community and choose it as the subject of their project [20-S-14].

- Category 3: Despite having heard about the trend of living 'zero waste', team members do not personally know any practitioner. They set out to contact people who identify with that lifestyle and gain some first-hand experience in the meantime [19-J-29].

- Category 4: A team consisting of students who aspire to join the armed forces and already know some people there still consider the army as a strange community which they choose to explore in their project [20-S-27].

A second aspect of the students' approach to strangeness concerns the nature of their engagement with the chosen subject. While some teams opted for a relatively safe approach (e.g., interviewing an acquaintance), other teams acted more in accordance with the spirit of the task by stretching beyond their comfort zones (e.g., going to locations they have never visited and feel some uneasiness about). This resulted in a variety of complementary engagements ranging from explorations on the internet and on-site observations, over various forms of interviewing (structured, semi-structured, or unstructured; conducted by one or by more members; oral or in chat boxes; single or iterative), to more immersive experiences (e.g., participating in a Live Action Role-Playing game; living zero waste for several days; joining Buddhist meditation practice). It must be noted that the cohort of 2020 faced severe restrictions as a result of the Covid-19 contingency measures and in many cases, teams resorted to virtual encounters out of necessity. Nevertheless, there were also teams that found inventive ways of engaging directly with their subject within the limitations of the home setting (e.g., finding 
strangeness by exploring their own parents' accounts of life as young adults; or choosing local supermarkets as the observation site, one of the only places where people gathered during the lockdown). Finally, a number of good practices could be identified where students mobilized team cultural diversity (associated with identity markers such as family composition, religious beliefs, place of residence, and home languages) to define their subject, to widen the range of accessible sources, or to enrich the interpretation by articulating and comparing different perspectives on the encounter within the team.

Broadly speaking, we can conclude that students located strangeness in subjects that appeared familiar at first sight as well as in subjects far outside their comfort zone. In the former case, they made the familiar look strange again; in the latter they familiarized themselves with what was originally seen as strange. Secondly, teams that adopted methodological triangulation and included immersive forms of engagement often demonstrated advanced intercultural learning. This was apparent from the analysis of actual demonstrations of critical interculturality in the student reports, as illustrated below. These findings have been helpful in coaching student teams during the initial stage of project formulation for setting up encounters that provide a conducive setting for intercultural learning.

\section{RQ2: What have students learned from their EWS project?}

In order to gain insight into students' learning gains, we first considered what they themselves cited as takeaways from their projects. As illustrated in Figure 3, a central conclusion students drew from the project is that personal experience and direct engagement with others truly make a difference. As one team puts it, 'Experience is the only true eliminator of all single stories one holds about different cultures and lifestyles' [Report 19-J-35]. (See Appendix 2 for the coding table and additional illustrative quotes.) Students further realized there are three qualities that should be brought to the experience to make it worthwhile: keeping an open mind (characterized by suspension of judgment, welcoming the unexpected, and recognizing the limits to knowledge); avoiding an essentialist view of culture; and being aware of stereotyping and prejudicing. Such awareness can help students to identify and then sidestep sources of bias while they conduct their projects. It can also help them to remain wary of media images, which, students state, should not be taken at face value but be tested through personal experience. These findings provide some validation of the experiential focus in the educational intervention, and we have found them useful to motivate particularly those students who may at first be apprehensive about an assignment that does not concern fixing some problem. 


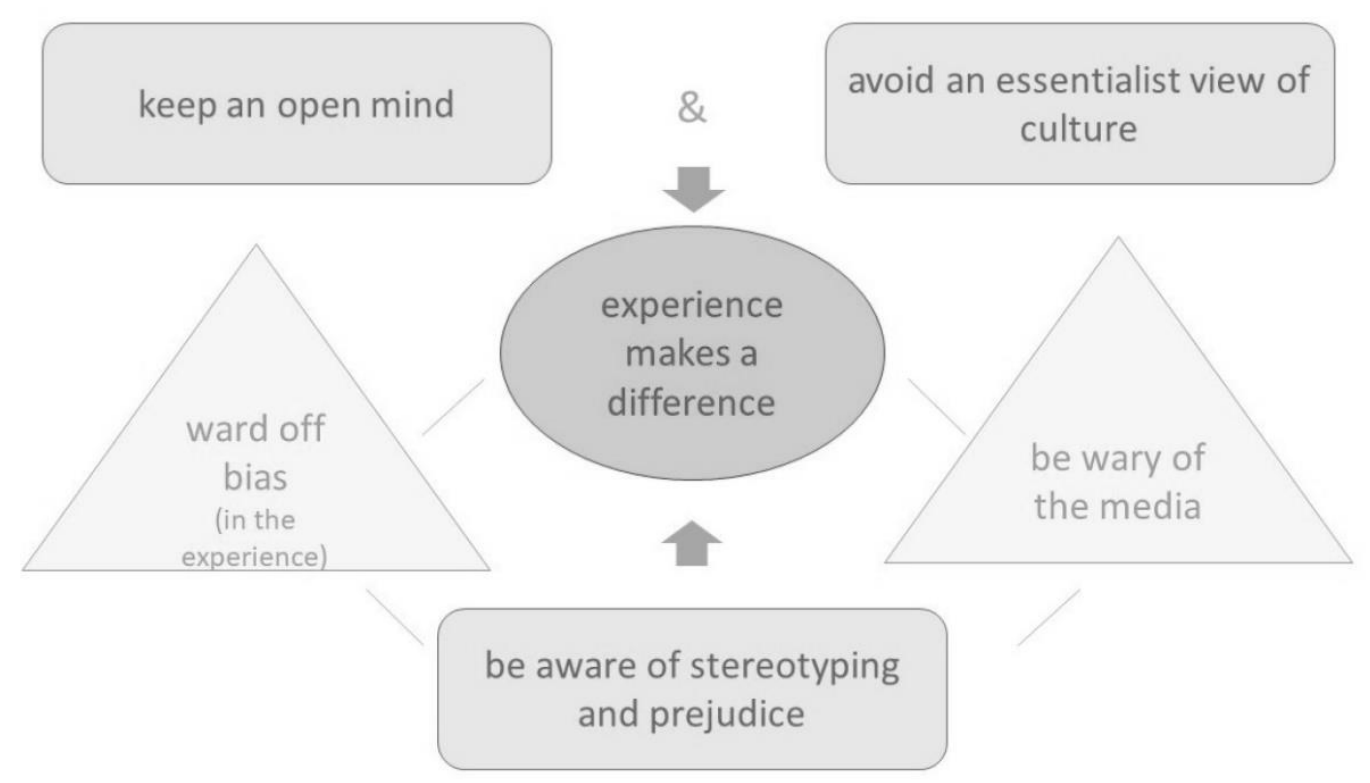

Figure 3. Thematic map of reported insights (based on the coding table in Appendix 2).

While the reported insights reveal the student perspective, as teachers we cannot entirely sidestep the issue of how to assess actual demonstrations of critical interculturality in the team reports. We analyzed student reports with this aim, using Holliday et al.'s (2017, pp. 58-59) disciplines for intercultural communication as a tool for identifying instances of conceptual (knowing that) or procedural understanding (knowing how to) of critical interculturality. The following illustrates this approach for a single report with reference to the three major themes from the textbook.

- Identity: Respond to people according to how you find them rather than according to what you have heard about them, building up thick descriptions along the way (based on disciplines 1 to 4 ).

- Othering: Monitor your own language and avoid falling into the culturist trap of reducing people to less than they are (based on disciplines 13 and 17).

- Representation: See through popular societal images and fictions from media, political and institutional influences, which may be deeply ingrained in our 'think-as-usual' truth and are easily perpetuated (based on disciplines 18 to 22).

The project concerned was conducted by a culturally diverse team of four female students who set out to interview a young student-mother. They used this encounter as a basis for self-reflection and team dialogue about their own and each other's 
pre-conceived ideas regarding the combination of motherhood and study. The first excerpt introduces their approach:

As the interviewers, the main goal is to analyze the young mother's experience from different cultural backgrounds, since we all came from different cultures, there are some diverse expectations. Thus, it would be interesting to reflect on our views about the encounter and see whether or not we fell in any of the intercultural communication traps that we learned throughout this course. Each part will be analyzed by a member of the team that found the experience interesting on a personal view level and then another member will analyze both based on intercultural communication elements [report 20-J-9, p. 1].

The description of their approach and the ensuing account by the students demonstrate that they know how to build up thick descriptions and avoid easy answers. In this sense, the report can be said to demonstrate procedural understanding of the first set of disciplines (identity). In the next excerpt, the students demonstrate declarative understanding of the second set of disciplines (othering). One student explains how her teammate Lily reduces interviewee Monica to the only image of the young student-mother Lily is familiar with, namely her own mother, and how this leads Lily to adopt 'false sharing' in her communication:

Monica is a young parent, like Lily's once were. Lily considered this to be a similar background, which affected her behavior and reactions towards Monica, for example by being more informal and expecting many similarities. This might be translated into essentialist communication ... as Lily thought she was being understanding solely by having the age parameter in common (Lily's mother) however without knowing Monica's complex background ... Lily thought she was being compassionate, by expressing feelings of similarity, assuming to understand Monica's 'young motherhood' but her assumptions were not correct [20-J-9, p. 4; pseudonymized].

Another student describes how her teammate Paradisa has been influenced by popular societal images in her community about struggling young mothers, which Paradisa refers to as 'the rule'. In this way, the team can be said to demonstrate declarative understanding of the third set of disciplines (representation): 
Paradisa had formed an essentialist view... as she thought that Monica was a pleasant exception to the 'rule'... being the stereotype of teen mum's lacking academic background ... [Paradisa's] preconceived idea about her was that Monica would be academically and financially struggling compared to other students who aren't mothers. Just a single aspect of Monica's identity, her being a mother, immediately created these false perceptions to Paradisa, which are solely based on the environment that she was brought up in [20-J-9, p. 5; pseudonymized].

Reports also contained numerous indications of a lack of critical understanding, for instance in cases where students take their interviewee's statements at face value or generalize them to an entire cultural group. In one example, a team interviewed a white man and former member of the military during the apartheid regime in South Africa to hear from a perspective that they were not familiar with. The interviewee depicted Nelson Mandela and his cronies as people who used to plan 'public bombings that killed many innocent victims, not to mention murders committed for political expedience and gain.' This led the students to conclude automatically and hence, uncritically that 'The media often ignores the wrongdoings of the side that is suffering and highlights the wrongdoings of the perpetrators. This definitely was the case in this situation' [20-J-28, p. 5]. Our exploratory analysis provided preliminary indications that Holliday, Hyde, and Kullman's disciplines have strong potential to be turned into a flexible tool for guidance and assessment (self-, peer-, and instructor-driven) of a critical understanding of intercultural communication, as will be discussed further below.

\section{Revisiting intercultural encounters as encounters with strangeness}

\section{Paradoxes and dialectics of strangeness}

Within the context of the EWS project, encountering strangeness appears quite a demanding challenge as it implies that students are able to handle at least three slippery paradoxes. As a first seeming contradiction, the project sets things up for encounters with a safe strangeness that nudges students out of their comfort zone towards ambiguity and uncertainty, but simultaneously protects them from levels of anxiety that we fear might hinder their learning. As a result, a genuine 'annoyance of being lost' (Hall, 1976, p. 46) has been a rare experience in the projects. A second paradox resides in the fact that we are asking students to define their topic of strangeness before the encounter has taken place. Since one can only name what is relatively (un)familiar (rather than what is utterly unknown or unknowable), it is not surprising that the projects focus on strangeness as 
unfamiliarity ('comparative strangeness', Srubar, 2005) and rarely address a more existential strangeness that is by definition irreducible to the familiar (Huett \& Goodman, 2014). A final paradox concerns how the project could be seen to impose openness on the students. An open mind is greatly valued as a requisite attitude for intercultural learning by scholars (Deardorff, 2006) and students (Van Maele, Vassilicos, \& Borghetti, 2016) alike but it remains a moot point whether willingness to engage with strangeness is a reasonable requirement in a compulsory school assignment.

Besides the abovementioned paradoxes, we can see also other dynamics at play in the tension between strangeness and familiarity. Referring back to de Jong et al.'s (2013) distinction between familiarization and estrangement strategies, we observed how student teams adopted a range of familiarization strategies for reducing strangeness, such as visiting hitherto unknown places, interacting with strangers, and trying out novel practices. Yet, there were also teams who made the opposite movement and mobilized estrangement strategies for making the familiar strange. Interestingly, students approached this tension as a trade-off, whereby an increase in familiarity naturally entails a decrease in strangeness, rather than as a paradox (for new facets of strangeness can also emerge during and thanks to a closer investigation of the subject). Invariably, strangeness appeared not a constant or solid phenomenon but rather a gradual and subjective process in constant flux (Verdooren, 2014). Student teams situated the subject of strangeness at different levels of proximity: outside their team, within the team (e.g., when they mobilized team cultural diversity to discuss their differing perspectives), and in some cases within themselves (as in Lily's case discussed above), acknowledging that we can be strangers to ourselves (Kristeva, 1988). However, regardless of the locus, students hardly transcended the duality of cultures by exploring the more elusive 'divergence' that opens up at boundaries (Jullien, 2009/2011).

In sum, the findings demonstrate that the EWS project can be conducive to experiencing the dialectic tension between strangeness and familiarity (Harbers, 2010) but at the same time they reveal there remains a reservoir of untapped potential for intercultural awareness raising. This is one limitation of the project as it has been implemented so far.

\section{Strangeness and criticality in EWS}

Another limitation concerns the fact that the degree of strangeness in the topic and the method of engagement appears neither as a necessary nor as a sufficient condition for achieving a more critical understanding of interculturality. It is not necessary because students who demonstrate critical understanding may obviously have developed this through experiences that took place before or outside the project. It is not a sufficient condition because the plain confrontation with 
strangeness in the project does not generate an adequate level of critical understanding by itself. That does not mean that encounters with strangeness are not a formative experience; just that the project by itself cannot be expected to have such effects any more than a student exchange stay can be expected to magically dissolve stereotypical images and prejudices (Jackson \& Oguru, 2018).

While there are clear indications that the EWS project promotes learning, we need to ask ourselves in how far that process has taken students to a more critical outlook. It would be useful to have a tool for (self-)assessing critical interculturality like the one derived from Holliday et al.'s (2017) disciplines for intercultural communication that we explored in this study. One advantage that we observed is that the disciplines create a shared language for students and teachers to report on and discuss their intercultural experiences. Yet, such a tool has to be applied with caution. Although students may well cite a fair range of disciplines in the reports, their references may be no more than token statements if they are unaccompanied by any actual demonstration of understanding. We also noted that students sometimes seem to confuse criticality with social desirability, as if culturist statements are acceptable as long as something positive is stated about the other. One particularly conspicuous demonstration of lack of critical understanding was the matter-of-fact attribution of bias to the media and other institutional influences within society. Team reports regularly contained admonitions against 'the media', which were ascribed unsubstantiated intentions or dismissed as 'fake news', while the students neglected to question their own share in holding certain assumptions.

\section{Conclusions}

The need to support engineering students in intercultural learning is rooted in the reality of an at once globalized, localized, and polarizing world. As engineering educators, it is our responsibility to prepare future engineers for working in a diverse context and to equip them with strategies to engage with the other while maintaining an open, curious mindset (Long, 2020; Vanasupa, 2020). This paper reported on one such educational intervention for undergraduate engineering students that centers on an encounter with strangeness. Within the context of engineering education, where the focus rests on enabling students to get a grip on the unknown through solutions, this project can remind students that it is just as important to come to terms with the unknown by understanding and accepting that situations cannot and need not always be reduced to fixable problems.

This study yielded some useful insights in the way students perceive and engage with strangeness, and how they see the impact of their encounter on their ongoing intercultural learning. As students were encouraged to determine for 
themselves what is 'strange' and how to engage with 'strangeness', a wide variety of encounters resulted, characterized by familiarization as well as estrangement strategies. Whether they chose their topic on the basis of existing relationships or of expectations about the future, students realized the power of first-hand experiences and recognized the key role of open-mindedness, avoidance of an essentialist view, and an awareness of stereotyping.

Educators will be interested to learn that the findings support the importance of team cultural diversity as a context for reflexive dialogue and examining different perspectives. As team members bring in their own experiences, views and values, these elements can become the strongest learning resource for practicing intercultural communication. The findings further suggest that the encounters can be enhanced when students venture into the stretch zone and combine several different methods of engagement with strangeness in their exploration. Providing guidance and support to the students during their learning path is of great value to stimulate meaning making from what they experienced during the encounter.

From a research point of view, it would be valuable to investigate the student perspective in greater depth to gain insight into the processes of how teams arrive at their choices and how they look back on their project in terms of the perceived contributions, challenges, and gains. Data could be collected through analyzing the existing tutorials and by arranging focus groups. It would be just as important to transcend the limitations of what students report by assessing actual demonstrations of critical understanding of interculturality. The paper explored the potential use of Holliday et al.'s (2017) disciplines for this purpose but further research is needed before firm conclusions can be drawn.

To conclude, Encounters with Strangeness embodies an experience-based methodology for intercultural learning that can successfully be integrated in the engineering curriculum. As such, it can help to fill the observed lack of intercultural communication practices from a critical and non-essentialist perspective in engineering education. More generally, this study hopes to contribute to a wider 'pedagogy of encounter' by elucidating the concept of strangeness as a linking concept for examining underlying dynamics in intercultural interaction. Even though enhanced critical understanding may not always be a guaranteed outcome, the project provides a context and a stimulus for students to grow through engaging with strangeness in diverse forms. 


\section{Author biographies}

Jan Van Maele teaches and researches communication at the Faculty of Engineering Technology, KU Leuven, Belgium. He holds a PhD in language assessment from Université Catholique de Louvain, Belgium. His main interests are intercultural interaction, international education, and language assessment. He has collaborated on international projects in these fields with partners in Europe, Asia, and Latin America, most recently as the coordinator of the Erasmus+ RICH-Ed project, which strives to develop a non-essentialist approach to interculturality in Chinese higher education. In recent years, he has been a visiting research scholar in China, Japan, and the UK.

Steven Schelkens teaches communication at the Faculty of Engineering Technology at KU Leuven. $\mathrm{He}$ is particularly interested in the impact of media images on society and the interaction between media and cultures. He is a former journalist for the public broadcaster VRT in Flanders, Belgium, where he contributed multiple stories about cultural and intercultural issues. Steven holds a master's degree in communication sciences from KU Leuven and a bachelor in radio and television journalism from KH Mechelen, Belgium.

Katrien Mertens is coordinator of the UNESCO-associated postgraduate program 'International Educating Class' at UC Leuven-Limburg (UCLL), Belgium. She also teaches courses on intercultural learning, personal growth and sustainable development. Currently she is researching the power of sharing stories in building empathy and connection. She has collaborated in various national and international projects on these themes, most recently in the Erasmus+ projects RICHEd (on interculturality in Chinese higher education) and ATTAIN (Accreditation and Training of Teacher Assistants in Bhutanese Schools). Katrien holds a master's degree in adult educational sciences from Vrije Universiteit Brussel, Belgium. 


\section{References}

ABET. (2019). Criteria for accrediting engineering programs. Effective for reviews during the 2020-2021 accreditation cycle. Baltimore, MD: ABET. Retrieved from https://www.abet.org/accreditation/accreditation-criteria/criteria-foraccrediting-engineering-/programs-2020-2021/

Bhabha, H. (1990). The third space. In J. Rutherford (Ed.), Identity: Community, culture, difference (pp. 207-221). London, UK: Lawrence and Wishart.

Borghetti, C. (2017). Is there really a need for assessing intercultural competence? Some ethical issues. Journal of Intercultural Communication, 44. http://mail.immi.se/intercultural/nr44/borghetti.html

Braun, V., \& Clarke, V. (2006). Using thematic analysis in psychology. Qualitative Research in Psychology, 3(2), 77-101. https://doi.org/10.1191/1478088706qp063oa

Dasli, M. (2011). Reviving the 'moments': From cultural awareness and cross cultural mediation to critical intercultural language pedagogy. Pedagogy, Culture \& Society, 19(1), 21-39. https://doi.org/10.1080/14681366.2011.527118

Deardorff, D. K. (2006). Identification and assessment of intercultural competence as a student outcome of internationalization. Journal of Studies in Intercultural Education, 10(3), 241-66. https://doi.org/10.1177/1028315306287002

Deardorff, D. K. (n.d). Process model of intercultural competence. Retrieved from http://www.guninetwork.org/articles/process-model-interculturalcompetence

Dervin, F. (2016). Interculturality in education: A theoretical and methodological toolbox. London: Palgrave Macmillan.

Dervin, F. (2017). Critical interculturality. Lectures and notes. Cambridge: Cambridge Scholars.

Devers, K. J., \& Franklin, R. M. (2000). Study design in qualitative research-2: Sampling and data collection strategies. Education for Health, (13)2, $263-$ 271.

Dewey, J. (2015). Experience and education. New York: Free Press. (Original work published in 1938)

EURANEE (2015). EUR-ACE framework standards and guidelines. Retrieved from https://www.enaee.eu/eur-ace-system/standards-andguidelines/\#standards-and-guidelines-for-accreditation-of-engineeringprogrammes

FEIAP (2010/2018). FEIAP Engineering education and accreditation guidelines 
for engineer. Retrieved from http://www.feiap.org/feiap-engineeringeducation-accreditation-guideline/

Geertz, C. (1973). The interpretation of cultures. New York: Basic Books.

Gudykunst, W. B., \& Kim, Y. Y. (1997). Communicating with strangers. An approach to intercultural communication ( $3^{\text {rd }}$ ed.). Boston, Mass: McGrawHill.

Hall, E. T. (1976). Beyond culture. New York: Anchor.

Hanchin, T. (2019). Encounter and/as pedagogy for Catholic higher education in our time. Religious Education, 114(5), 565-580. https://doi.org/10.1080/00344087.2019.1631975

Handford, M., Van Maele, J., Matous, P., \& Maemura, Y. (2019). Which ‘culture'? A critical analysis of intercultural communication in engineering education. Journal of Engineering Education, 108, 161-177. https://doi.org/10.1002/jee.20254

Harbers, H. (2010). Introduction. In H. Harbers (Ed.), Strangeness and familiarity. Global unity and diversity in human rights and democracy. Proceedings from FORUM Conference. Groningen: FORUM and the University of Groningen.

Hoffman, E., \& Verdooren, A. (2018). Diversity competence. Cultures don't meet, people do. Bussum: Coutinho.

Holliday, A. (1999). Small cultures. Applied Linguistics, 20(2), 237-264. doi.org/10.1093/applin/20.2.237

Holliday, A., Kullman, J., \& Hyde, M. (2017). Intercultural communication. An advanced resource book for students. London: Routledge.

Holmes, P., \& O’Neill, G. (2010). (Auto)ethnography and (self)reflection: Tools for self-assessing intercultural competence. In J. Tsau \& S. Houghton (Eds.), Becoming intercultural: Inside and outside the classroom. Cambridge: Cambridge Scholars.

Holmes, P., \& O’Neill, G. (2012). Developing and evaluating intercultural competence: Ethnographies of intercultural encounters. International Journal of Intercultural Relations, 36, 707-718.

Huett, S., \& Goodman, D. (2014). Alterity. In T. Teo (Ed.), Encyclopedia of critical psychology (pp. 82-87). New York: Springer. https://doi.org/10.1007/978$\underline{\text { 1-4614-5583-7 }}$

IEREST. (2015). Intercultural education resources for Erasmus students and their teachers. Koper: Annales University Press. Retrieved from http://www.ierest-project.eu/humbox.html

Jackson, J., \& Oguru, S. (2018). Enhancing and extending study abroad learning through intercultural interventions. In J. Jackson \& S. Oguru (Eds.), Intercultural interventions in study abroad (pp. 1-17). London: Routledge. 
Jong, M. de, Kamsteeg, F., \& Ybema, S. (2013). Ethnographic strategies for making the familiar strange: Struggling with 'distance' and 'immersion' among Moroccan-Dutch students. Journal of Business Anthropology, 2(2), 168186.

Jullien, F. (2011). The silent transformations. London: Seagull. (Original work published in 2009)

Kjellgren, B. (2020). Ways and benefits of closing the gap: Aligning language and communication teaching with the technical curriculum. 2020 IEEE Global Engineering Education Conference (EDUCON) (pp. 1266-1271). Porto, Portugal. https://doi.org/10.1109/EDUCON45650.2020.9125199

Kramsch, C. J. (2011). The symbolic dimensions of the intercultural. Language Teaching, 44(3), 354-367. https://doi.org/10.1017/S0261444810000431

Kristeva, J. (1988). Étrangers à nous-mêmes. Paris: Gallimard.

Limacher, U. (n.d.). Why comfort zone and stretching zone can be (almost) one?

Retrieved from www.utesinternationallounge.com/why-comfort-zone-andstretching-zone-can-be-almost-one/

Long, L. L. (2020). Toward an antiracist engineering classroom for 2020 and beyond: A starter kit. Journal of Engineering Education, 109(4), 636-639. https://doi.org/10.1002/JEE.20363

MacDonald, M. N. (2019). The discourse of 'thirdness' in intercultural studies. Language and Intercultural Communication, 19(1), 93-109. https://doi.org/10.1080/14708477.2019.1544788

Marotta, V. (2012). Georg Simmel, the stranger and the sociology of knowledge. Journal of Intercultural Studies, (33)6, 675-689. https://doi.org/10.1080/07256868.2012.739136

Moser, A., \& Korstjens, I. (2018). Practical guidance to qualitative research. Part 3: Sampling, data collection and analysis. European Journal of General Practice, (24)1, 9-18. https://doi.org/10.1080/13814788.2017.1375091

Polymenakou, E. (2019). Student teachers' intercultural learning through pedagogical intercultural community encounters in Greece. (Unpublished doctoral dissertation). University of Bath, U.K. Retrieved from https://researchportal.bath.ac.uk/en/studentTheses/student-teachersintercultural-learning-through-pedagogical-inter

Prechtl, E., \& Lund, A. D. (2007). Intercultural competence and assessment: perspectives from the INCA project. In H. Kotthoff \& H. Spencer-Oatey (Eds.), Handbook of intercultural communication (pp. 467-490). Berlin: Mouton de Gruyter.

Rico-García, M. \& Fielden Burns, L. V. (2020) Intercultural communication in 
engineering studies: A key competence in global labour markets. European Journal of Engineering Education, 45(6), 833-853. https://doi.org/10.1080/03043797.2019.1654980

Samudra, J. K. (2008). Memory in our body. Thick participation and the translation of kinesthetic experience. American Ethnologist, 35(4), 665-681. https://doi.org/10.1111/j.1548-1425.2008.00104.X

Seaman, J., Brown, M., \& Quay, J. (2017). The evolution of experiential learning theory: Tracing lines of research in the JEE, Journal of Experiential Education, 40(4), 1-21. https://doi.org/10.1177/1053825916689268

Simmel, G. (1908 / 1999). The stranger. In G. Lemert (Ed.), Social theory: The multicultural and classic readings (pp. 184-189). Boulder, CO: Westview Press.

Simpson, A., \& Dervin. F. (2019). The Council of Europe Reference Framework of Competences for Democratic Culture: Ideological refractions, othering and obedient politics. Intercultural Communication Education, 2(3), 102119. https://dx.doi.org/10.29140/ice.v2n3.168

Srubar, I. (2005). The pragmatic theory of the Life-World as a basis for intercultural comparison. In M. Endress, G. Psathas, \& H. Nasu (Eds.), Explorations of the Life-World. Continuing dialogues with Alfred Schutz (pp. 235-266). Dordrecht: Springer.

Ting-Toomey, S. (1999). Communicating across cultures. New York: Guilford.

Vanasupa, L. (2020). From 2020 vision: engineering education that honors the whole. Journal of Engineering Education. https://doi.org/10.1002/jee.20327

Van Maele J., \& Mertens K. (2014). Towards an experience-driven approach to teaching intercultural communication. In P. Romanowski (Ed.), Studia Naukowe, 27, Intercultural issues in the era of globalization (pp. 122-129). Warsaw: IKSI Scientific Publishing House.

Van Maele J., \& Vassilicos B. (2015). Making way for the intercultural in engineering education: New spaces for embracing the tensions. In K. Hawash \& C. Léger (Eds.), Diversity in engineering education: An opportunity to face the new trends of engineering (art.nr. 56344). SEFI Société Européenne pour la Formation des Ingénieurs.

Van Maele J., Vassilicos B., \& Borghetti C. (2016). Mobile students' appraisals of keys to a successful stay abroad experience: Hints from the IEREST project. Language \& Intercultural Communication, 16 (3), 384-401. https://doi.org/10.1080/14708477.2016.1168050

Verdooren, A. (2014). Taking multiplicity seriously: Towards new approaches for intercultural practitioners. Interculture Journal, 13(23), 11-24. 
Appendix 1. Reported motives.

\begin{tabular}{|c|c|c|c|}
\hline \multicolumn{4}{|c|}{ Reported motives } \\
\hline Theme & Code & Includes references to & Illustrative quote \\
\hline \multirow{4}{*}{$\begin{array}{l}\text { Because of what? } \\
\text { (interest) }\end{array}$} & Practical value & $\begin{array}{l}\text { Student interest based on convenience or } \\
\text { practical organisation }\end{array}$ & $\begin{array}{l}\text { "We chose people we knew, this way we could reach out easily and the } \\
\text { interviews would be less awkward." [20-s-17] }\end{array}$ \\
\hline & Topical value & $\begin{array}{l}\text { Student interest in the topic without any } \\
\text { additional reported motives }\end{array}$ & $\begin{array}{l}\text { "We are all interested in this subject because everyone has heard of } \\
\text { Muslims but knows very little." [20-S-41] }\end{array}$ \\
\hline & Emotional value & $\begin{array}{l}\text { Student interest in the emotional connection to } \\
\text { the topic: fascinated, intrigued, triggered, } \\
\text { curious, involved, ... }\end{array}$ & $\begin{array}{l}\text { "after hearing about it from other team members, were intrigued by } \\
\text { China's cultural history." [20-J-31] }\end{array}$ \\
\hline & Opportunity value & $\begin{array}{l}\text { Student interest in the opportunity of } \\
\text { conducting the project }\end{array}$ & $\begin{array}{l}\text { "A great opportunity to conduct a real experiment and experience } \\
\text { ourselves how the process of changing the prejudices feels and is } \\
\text { realized." [19-J-3] }\end{array}$ \\
\hline \multirow{5}{*}{$\begin{array}{c}\text { For what purpose? } \\
\text { (expectation) }\end{array}$} & Acquire understanding & $\begin{array}{l}\text { Student expectation to acquire a greater } \\
\text { understanding: know what/how; find out if; } \\
\text { get/obtain a better understanding; see (e.g., } \\
\text { what it encompasses) ... }\end{array}$ & $\begin{array}{l}\text { "The goal of our investigation was to understand the thousands of people } \\
\text { that roam the streets for the environment." [19-S-37] }\end{array}$ \\
\hline & Change own views & $\begin{array}{l}\text { Student expectation to question their } \\
\text { perceptions and change their perspectives }\end{array}$ & $\begin{array}{l}\text { "we decided to experience Buddhism and try to rid ourselves of the single } \\
\text { stories we held, that we knew and that we didn't know we had." [19-J-35] }\end{array}$ \\
\hline & & & \\
\hline & Change others' views & $\begin{array}{l}\text { Student expectation to demonstrate/show/ } \\
\text { prove/debunk ... something (to the reader; to } \\
\text { people in general) }\end{array}$ & $\begin{array}{l}\text { "We want to prove that these standpoints towards unknown sports are } \\
\text { indeed misconceptions and false use of stereotypes." [20-S-4] }\end{array}$ \\
\hline & Future benefit & $\begin{array}{l}\text { Student expectation to acquire insight that will } \\
\text { benefit or help them in future }\end{array}$ & $\begin{array}{l}\text { "Now we got to know the culture hands on it is easier for us to understand } \\
\text { and to support others who do." [19-S-12] }\end{array}$ \\
\hline
\end{tabular}


Appendix 2. Reported insights and takeaways.

\begin{tabular}{|c|c|c|c|}
\hline Theme & & $\begin{array}{l}\text { Reported insights and tak } \\
\text { includes references to }\end{array}$ & reaways \\
\hline \multirow{4}{*}{$\begin{array}{l}\text { to keep an open } \\
\text { mind }\end{array}$} & openness & $\begin{array}{l}\text { openness; open-mindedness; opening up } \\
\text { (e.g., beyond primary instincts); } \\
\text { disconnecting (e.g., from what you know) } \\
\text {... }\end{array}$ & $\begin{array}{l}\text { "we learned a lot because we and the [vegetarian] family [we } \\
\text { visited] were open minded [...] Open mindedness [sic]: a } \\
\text { strategy we could recommend for all intercultural encounters." } \\
\text { [19-s-12] }\end{array}$ \\
\hline & withholding of judgment & $\begin{array}{l}\text { not judge (e.g., a book by its cover; on first } \\
\text { sight); not make judgments (e.g., before } \\
\text { you get to know the other); put aside } \\
\text { biased views (e.g., and listen) ... }\end{array}$ & $\begin{array}{l}\text { "Useful lessons are that we should not judge on first sight. If } \\
\text { culture writes prostitution off, that does not mean you should } \\
\text { not listen or try to understand." [20-J-15] }\end{array}$ \\
\hline & welcoming the unexpected & (all references to being surprised) & $\begin{array}{l}\text { "Buddhism was a lot different than any of us imagined [...] We } \\
\text { discovered that there is a lot more diversity within the Buddhist } \\
\text { community than we previously believed" [19-J-35] }\end{array}$ \\
\hline & recognizing limits to knowledge & $\begin{array}{l}\text { (acknowledgments that certain things are } \\
\text { beyond our perception or understanding) }\end{array}$ & $\begin{array}{l}\text { "Our major perception with this work is that the world is vast } \\
\text { and there is an infinite amount of details in every culture that is } \\
\text { too hard for our simple minds to grasp." [19-J-TasteOfAfrica] }\end{array}$ \\
\hline $\begin{array}{c}\text { to avoid an } \\
\text { essentialist view } \\
\text { of culture }\end{array}$ & avoiding an essentialist view of culture & $\begin{array}{l}\text { losing an essentialist view; avoiding } \\
\text { essentialist descriptions; shifting to a non- } \\
\text { essentialist view ... }\end{array}$ & $\begin{array}{l}\text { "As a takeaway from this experience, we aim to avoid using } \\
\text { essentialist descriptions based on our observations." [20-S-14] }\end{array}$ \\
\hline \multirow{3}{*}{$\begin{array}{l}\text { to be aware of } \\
\text { stereotyping } \\
\text { and prejudicing }\end{array}$} & $\begin{array}{c}\text { awareness of stereotyping and } \\
\text { prejudicing }\end{array}$ & $\begin{array}{l}\text { the impact; origin; development; presence } \\
\text { of stereotypes and prejudices }\end{array}$ & $\begin{array}{l}\text { "prejudices have a larger impact than we thought in advance } \\
\text { [...] doing the interviews and hearing it from people that } \\
\text { actually experienced faulty prejudices about them or their } \\
\text { background made a lasting impression on us [...] Now that we } \\
\text { really know the impact of prejudices, each member of the } \\
\text { group decided to pay attention not to develop these prejudices } \\
\text { ourselves." [20-J-7] }\end{array}$ \\
\hline & the truthfulness of stereotypes & $\begin{array}{l}\text { debunk; disprove stereotypes; false; faulty } \\
\text {... stereotypes } \\
\text { correct; true ... stereotypes }\end{array}$ & $\begin{array}{l}\text { "By visiting the }[. . .] \text { settlement and talking to some of the } \\
\text { devotees we were able to debunk most of these prejudices } \\
\text { [...] We can conclude that not all stereotypes are completely } \\
\text { false, but most times they aren't correct at all. This means, in } \\
\text { general it's wrong to have stereotypes about other people, but } \\
\text { you also shouldn't just throw away your thoughts." [19-J-37] }\end{array}$ \\
\hline & awareness of single stories & $\begin{array}{l}\text { single stories / narratives; a variety of } \\
\text { stories / narratives }\end{array}$ & $\begin{array}{l}\text { "we can conclude that when looking at a climate march or a } \\
\text { similar group that is constantly covered by a variety of media, it } \\
\text { is important to stay aware of the very diverse variety of } \\
\text { narratives that is present among participants or members of } \\
\text { such a group" [19-J-6] }\end{array}$ \\
\hline $\begin{array}{l}\text { experience } \\
\text { makes a } \\
\text { difference }\end{array}$ & personal experience & $\begin{array}{l}\text { (all references to the experience of } \\
\text { conducting the project) } \\
\text { connection; interaction; social contact; } \\
\text { talking to; engaging with; visiting; spending } \\
\text { time with ... }\end{array}$ & $\begin{array}{l}\text { "Experience is the only true eliminator of all single stories one } \\
\text { holds about different cultures and lifestyles." [19-J-35] } \\
\text { "Understanding others on an emotional level requires engaging } \\
\text { with them and spending time with them." [20-J-22] }\end{array}$ \\
\hline \multirow[t]{2}{*}{ warding off bias } & $\begin{array}{c}\text { sources of bias (while conducting the } \\
\text { project) }\end{array}$ & $\begin{array}{l}\text { bias in what we believe; observe; read; } \\
\text { say; are told ... (while conducting the } \\
\text { project) }\end{array}$ & $\begin{array}{l}\text { "The most important lesson we learned when doing the } \\
\text { interviews was the fact that our questions were too loaded } \\
\text { and biased. In the formulation of the questions we sometimes } \\
\text { were already assuming a certain answer." [20-J-41] }\end{array}$ \\
\hline & information & $\begin{array}{l}\text { being informed; the need for gathering; } \\
\text { acquiring; checking information }\end{array}$ & $\begin{array}{l}\text { "The more informed we are about another group of people } \\
\text { and their situation the more we will understand and realize } \\
\text { why they do what they do." [20-J-22] }\end{array}$ \\
\hline $\begin{array}{l}\text { to be wary of } \\
\text { the media }\end{array}$ & awareness of (negative) media impact & $\begin{array}{l}\text { be aware of; vigilant about; not to accept; } \\
\text { not to be bound by ... images depicted in; } \\
\text { imprinted by ... the media } \\
\text { to fall victim to; }\end{array}$ & $\begin{array}{l}\text { "We certainly also have fallen victim to believing things we see } \\
\text { on shows too easily, that's why it's important that we should } \\
\text { stay vigilant about the things the media shows us." [20-S-14] }\end{array}$ \\
\hline
\end{tabular}

